\title{
THE IMMUNOSUPPRESSANT EFFECT COMPARATION BETWEEN ETHYL ACETATE AND N-BUTANOL FRACTIONS OF KALANCHOE PINNATA (LMK) PERS IN 2,6,10,14 TETRAMETHYLPENTADECANE-TREATED MICE
}

\author{
Niken Indriyanti ${ }^{1}{ }^{*}$, Joewono Soeroso ${ }^{2}$, Junaidi Khotib ${ }^{3, \dagger}$ \\ Department of Pharmacology, Faculty of Pharmacy, Universitas Mulawarman, Samarinda, \\ Indonesia ${ }^{1)}$ \\ Department of Internal Medicine, Faculty of Medicine, Universitas Airlangga, Surabaya, \\ Indonesia ${ }^{2}$ \\ Department of Clinical Pharmacy, Faculty of Pharmacy, Universitas Airlangga, Surabaya, \\ Indonesia $^{3)}$ \\ Corresponding author: niken@farmasi.unmul.ac.id*; junaidi.k@ff.unair.ac.id ${ }^{\dagger}$
}

\begin{abstract}
Immunosuppressant drugs are the main treatment of lupus patient. The ACR and SLICC treatment guidelines are able to increase the quality of life, but the outcome is not satisfying since the off-label therapy of corticosteroids and cytotoxic drugs give a lot of side effects. Many breakthrough efforts still develop in order to find the safe and effective drugs for lupus, such as finding immunosuppressant drugs from natural resources. One of the potential resources is Kalanchoe pinnata (Lmk) Pers, which have immunosuppressant, antiinflammatory, antinociceptive, and antioxidant effects. Thus, in the previous study, we found the effect of the aqueous extract of Kalanchoe pinnata (Lmk) Pers is active to repair the lupus manifestation in 2,6,10,14 tetramethylpentadecane (TMPD)-treated mice. Then, this research was focused on the in vivo immunosuppressant effect of a flavonoid-rich fraction of the extract which was consisted of the ethyl acetate (FE) and n-butanol (FB) fractions. The induction method and the extraction procedure were the same as the previous study and then the fractionation was performed by using liquid-liquid extraction. After 2-week treatment of both fractions, we obtained the differences in the total leukocytes, organ indexes, and also the spleen, kidney, and joint structure parameters. The total leukocyte of the FE group was 3,600 264 cells $/ \mathrm{mm}^{3}$, which was lower than that in the FB group. The spleen and kidney indexes increased after the administration of $F B$ fraction, while the $F E$ fraction was not. At last, despite the histology observation of spleen resembled mild structural changes differences, the clear differences between both treatment groups occurred in the kidney and joint histology. The differences led to a conclusion that the FE fraction has the better immunosuppressant effect in TMPD-treated mice.
\end{abstract}

Keywords: lupus model, Kalanchoe pinnata (Lmk)Pers, flavonoids, ethyl acetate fraction, n-butanol fraction

\section{INTRODUCTION}

Systemic lupus erythematosus (SLE) is a complex autoimmune disease whereas the immune system attacks their normal cells and tissues. Many factors contributed in the lupus pathogenesis are genetics, epigenetics, environment, and hormones (Comte, 2015). According to the epidemiology data of 24 countries in Asia, it could be predicted that the lupus 
prevalence is $30-50$ per 100,000 people (Salido and Manapat, 2010) while the gender ratio between female and male is 9-14: 1 (Bertoli, 2007; Danchenko, 2006).

Besides, the lupus mortality rate is almost 5 times higher than the normal (Jacobsen, 1999; Abu Shakra, 1995), and there is no latest data explain the present rate. The limitations of the drug used lead the researcher to find lupus drug candidates from many sources, such as natural resources. One of the potential medicinal plants which easily grow in Indonesia is Kalanchoe pinnata (Lmk) Pers because of its anti-inflammatory, antinociceptive, immunosuppressant, and antioxidant activities (Bergmann, 1994; Ferreira, 2014, Coutinho, 2012). In our previous study, the aqueous extract of Kalanchoe pinnata (Lmk) Pers leaves could repair some lupus manifestation in the TMPDtreated lupus mice. According to many published data, the flavonoid compounds in this plant could reduce the level of proinflammatory cytokines and also has a suppressive activity on T cells (Cruz et al., 2012; Coutinho et al., 2012). The main flavonoid that has proved as an antiinflammatory agent is quercetin $3-O-\alpha$-Larabinopyranosil $\quad(1 \rightarrow 2) \quad \alpha$-Lrhamnopyranoside (Ferreira, 2014). The flavonoid compounds will separate by using ethyl acetate solvent (Cruz, 2012). Therefore, the flavonoid-rich fraction would be more potent. However, the flavonoids are not only separated by ethyl acetate solvent but also by n-buthanol solvent. Thus, this research conducted to observe the differences effects between the ethyl acetate and n-buthanol fraction of Kalanchoe pinnata (Lmk) Pers leaves in the TMPD-treated lupus mice.

\section{METHODS}

\section{Materials}

The Kalanchoe pinnata (Lmk) Pers fresh leaves were obtained from a cultivation farm in Trenggalek, East Java. The botany identity of this plant was performed by Conservation Unit of Indonesian Institute of Science, Purwodadi with the identification number of 0284/IPH.06/HM/II/2015. The chemicals used in the fractionation were obtained from Merck through PT. Dianum as Indonesian supplier.

The female Balb/c mice aged 4 weeks were received from LPPT Gadjah Mada University, Indonesia. These mice were pathogen free species with the certificate number of 352/LP3HP/29/VII/2015. They were housed, randomized, and handled by using standard maintenance on the Guide of the Care and Use of Laboratory Animal $8^{\text {th }}$ edition, published by National Research Council.

TMPD (Pristane) with the code number of Sigma-P2870 was obtained from a Sigma-Aldrich supplier in Singapore, while the reagents and materials used in the hematoxylin-eosin staining were obtained from the veterinary pathology laboratory, Universitas Airlangga.

\section{Methods}

The aqueous extract of Kalanchoe pinnata (Lmk) Pers was dried by using freeze-dryer (Eyela), and then it was separated according to Cruz (2012) protocol. The ethyl acetate (FE) and nbutanol (FB) fraction were obtained by liquid-liquid extraction method. The dose of each tested fractions was decided based on the optimum dose of aqueous extract in the previously research and then extrapolated to the yields.

The tested fractions were given to each experimental group (FE and FB groups, 3 mice per group), meanwhile the naïve mice group received placebo. The mice used were female Balb/c mice aged 7 weeks. They were induced intraperitoneally by means of TMPD at the dose of $0.5 \mathrm{ml}$ per mice, once every 90 days. After 5 months induction time, the treatment was started and lasted for 2 weeks. After 7-day treatment, the total 
leukocytes were counted by using Neubauer-impruved hemocytometer. After a 2-week treatment, the mice were sacrificed. The spleen and kidney were weighed and then prepared for haematoxylin-eosin (HE) staining. The joint was also prepared. The histology changes of spleen and kidney were observed by facilitating of inverted microscope Olympus CXK410 with the magnitude of 400x, while the joint was observed at a magnitude of $40 x$.

\section{RESULTS AND DISCUSSION}

The TMPD-treated mice result in lupus-like disease mice with systemic immune imbalance, resemble lupus in human (Reeves, 2009). The induction process achieves the severe lupus model after 6 months according to Satoh (1999), Calvani (2003), and Leiss (2013). It was time-consuming and become a limitation in this research. In the previous study, we performed the validation of the mice model. The ascites manifestation and the anti-nuclear antibody occurred after 2 months induction, whether the level of proteinuria was elevated after 6-month induction.

In this research, the mice which have proteinuria level of $+( \pm 15 \mathrm{mg} / \mathrm{dL})$ were given the tested fraction each group. The naïve group received aquadest during the treatment. After seven days, the blood of each mouse was collected to measure the total leukocytes. The result is shown in Table 1.

Table 1 The total leukocytes of each experimental group after the 7-day treatment

\begin{tabular}{lc} 
Groups & Total leukocytes Count $\left(\mathrm{cell} / \mathrm{mm}^{3}\right)$ \\
\hline FE & $3600 \pm 264^{*}$ \\
FB & $8200 \pm 1838$ \\
Naïve & $9800 \pm 1698$
\end{tabular}

* Significantly different with others $(P<0.05)$

Table 2 Organ indexes of each experimental group

\begin{tabular}{lccc}
\hline \multirow{2}{*}{ Groups } & \multicolumn{3}{c}{ Indexes (\%) } \\
\cline { 2 - 4 } & Spleen & Kidney & Liver \\
\hline FE & 215,8 & 107,9 & 125,9 \\
FB & 342,6 & 185,5 & 127,4 \\
Naïve & 100 & 100 & 100 \\
\hline
\end{tabular}

The result resembles the antiinflammatory effect of ethyl acetate fraction of Kalanchoe pinnata (Lmk) Pers which is higher than its n-butanol extract effect. This effect is beneficially used in lupus condition because there is a systemic inflammation that increases the white blood cells production. This antiinflammatory effect is fit to the Ferreira's research result (2014).

After the treatment period finished, the mice were sacrificed by using cervical dislocation method. The spleen, liver, kidney, and joint were separated to be weighed and prepared for histology observation. The spleen and liver, the swelling organs, were calculated as the organ indexes compared to naïve mice. The result is shown in Table 2.

The result shows the swelling spleen and kidney in both TMPD-treated groups. The spleen of FE and FB groups swells 2-3 times higher than the normal one. It shows the immune-regulation imbalance resulted from the TMPD effect is processed to be conquered by the spleen 
functions. The spleen cells proliferated to produce the cytokines as an effort to block the immune reactivity. The $\mathrm{T}$ regulators are produced in this organ as immune homeostasis (Rifa'i, 2011). The spleen index of FE group is lower than the FB group, resembles the effect of the ethyl acetate fraction that could reduce the spleen inflammation process better than another.

Then, despite the swelling kidney in the FB group, the kidney index of FE group achieves the normal index. It

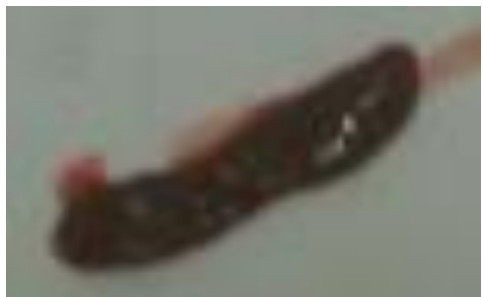

(a) predicted the higher activity of active compounds in the ethyl acetate fraction. At last, the liver index slightly increased but it might be a compensation of the systemic disorder. No other data explain the liver role in the systemic lupus pathogenesis progresses.

In the organoleptic observation, we found a new fact that there was a layer which was similar to lipid layer present on the spleen surface of the TMPD-treated mice (Figure 1), while the naïve mouse did not show it.

Figure 1 The appearance of the spleen of (a) the FE group and (b) FB group

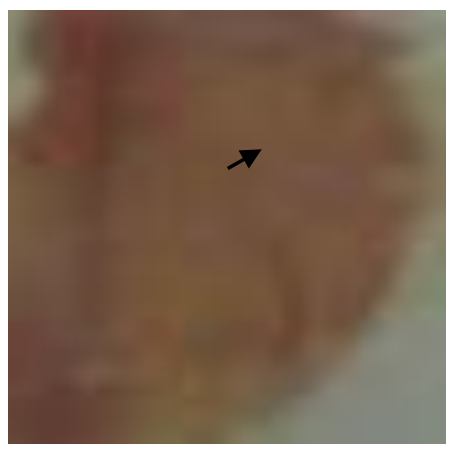

(a)

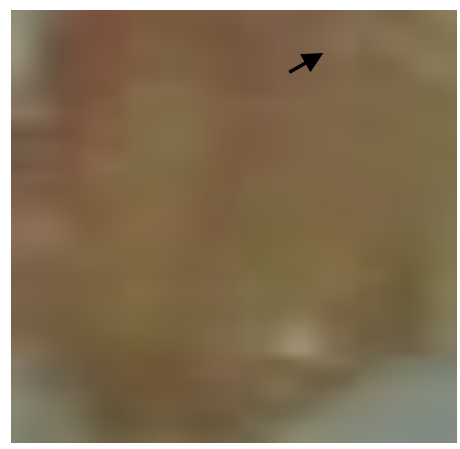

(b)

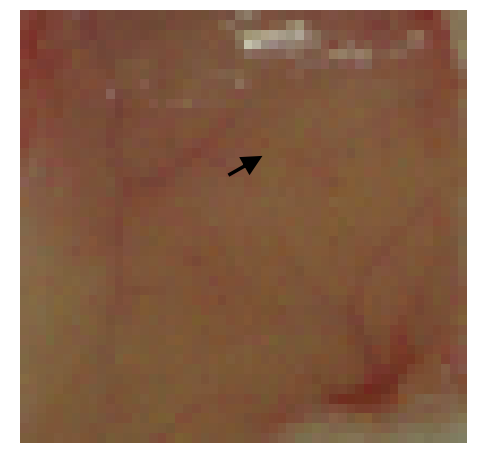

(c)

Figure 2 The lipogranuloma deposits in the peritoneal mucosa of (a) the FE group, (b) FB group, and (c) naïve group

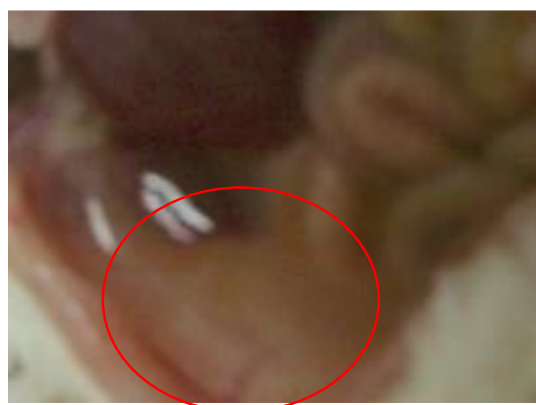

Figure 3 The fluid accumulated in the peritoneal cavity of lupus mouse 


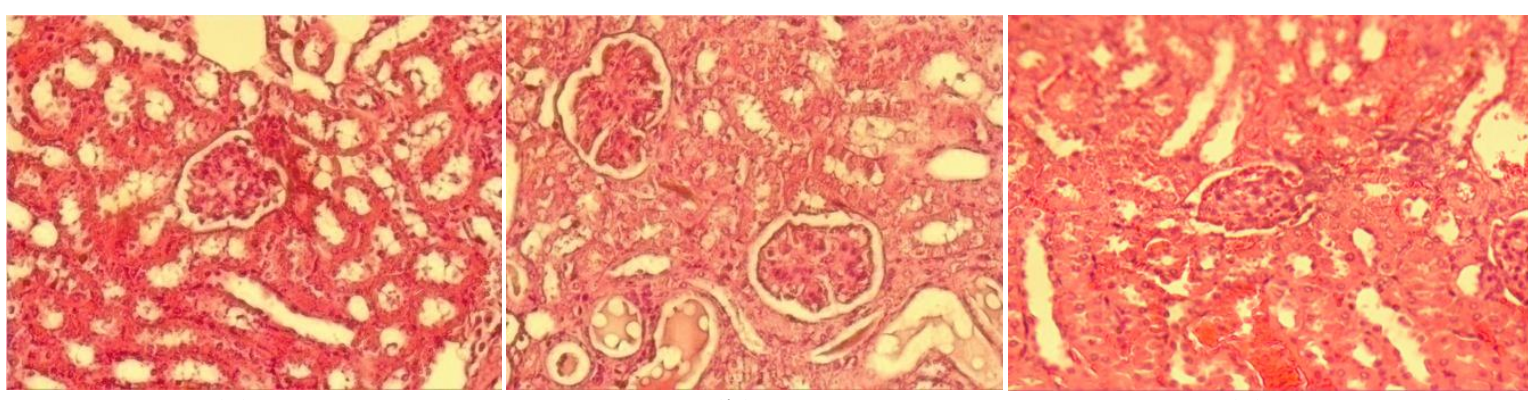

(a) (b)

Figure 4 The kidney histology observation of FE group (a); FB group (b), and naïve group (c) with the magnitude of 400x by utilizing of inverted microscope Olympus CKX410.

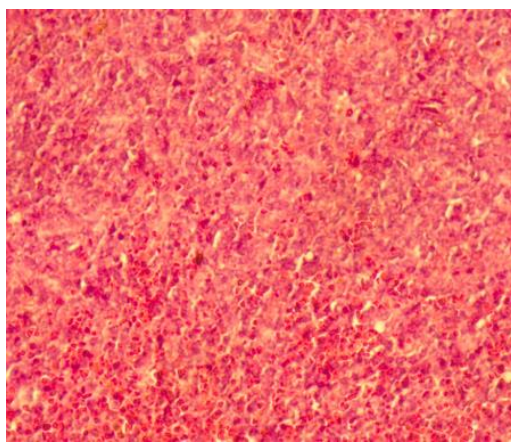

(a)

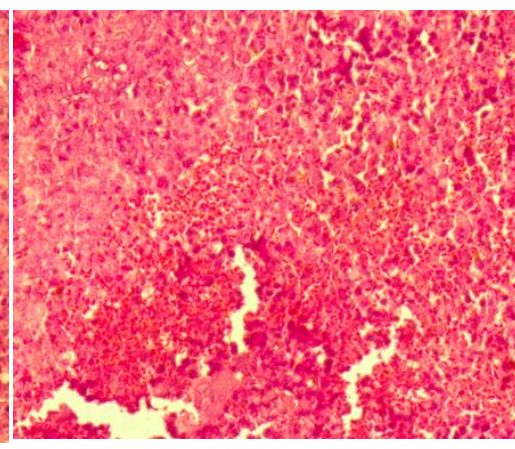

(b)

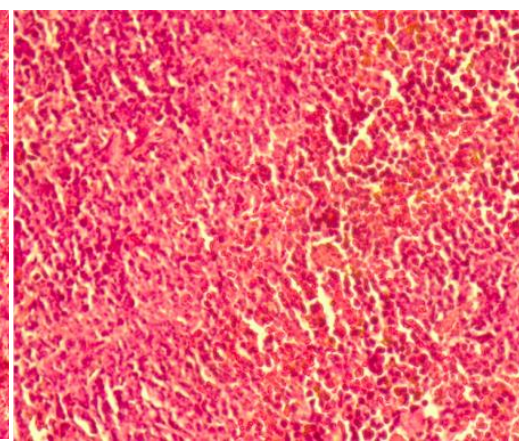

(c)

Figure 5 The spleen histology observation of FE group (a); FB group (b), and naïve group

(c) with the magnitude of 400x by utilizing of inverted microscope Olympus CKX 410 .

This characteristic is predicted to be linked to the calcification of the spleen as reported by Tieng et al. (2011). However, the further observation is needed to prove this prediction. Then, the lipogranuloma in the peritoneal cavity looks thinner in the FE group rather than FB group. The result is shown in Figure 2.

Beside the lipogranuloma, the ascites fluid volume was not accumulated in the treated groups. In the TMPD-treated mouse which was not received any treatment, we found the clear and viscous fluid filled in the peritoneal cavity (Figure $3)$. The histology observations were performed by using 4-6 $\mu \mathrm{m}$ thickness of tissues. The results are shown in Figure 46.

The figure shows the irregular structure of kidney tissue of the TMPDtreated mice. There are deposits of inflammatory cells which proliferate in the glomerulus. The wire loop looks thickened, and the mesangium areas are also thickened. However, the kidney structure of FE group looks better than the FB group. The further assessment is needed to know the class of its severity. Then, the second morphology observation is the spleen tissue (Figure 5).

The spleen is an important lymphoid secondary organ that regulates the immune balance in mammals. This histology observation could not explain a lot about the spleen function disorder, but there is a different distribution of the red pulps and the white pulps. It shows the accumulation of the red blood cells and white blood cells in the spleen. We could not predict or conclude anything from the spleen structure because there is no morphological significant differs. It needs a confirmation about the level of cytokines secreted by the spleen to predict what kind of functional disorder occurred.

Then, the observation conducted 
to the joint structure. Arthritis is a common manifestation in the systemic lupus erythematosus. The specific joint disorder affects the joint in the hand and knee. The periarticular structure swells and results in tendonitis, tenosynovitis, and tendon rupture. Avascular necrosis
$(\mathrm{AVN})$ is also occurred, causes pain and joint disability mainly in the big joints, such as hip and knee (Grossman, 2009). Therefore we observe the structure of the joint at the knee. The result is shown in Figure 6.

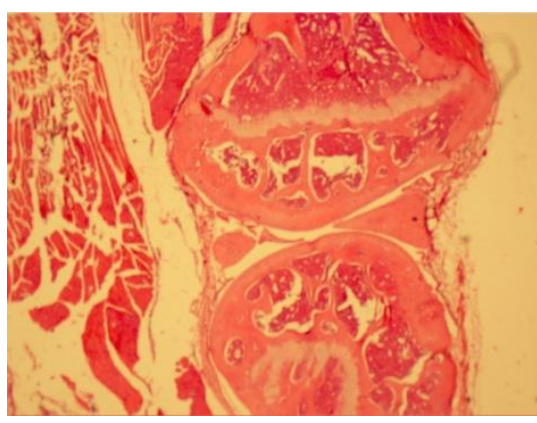

(a)

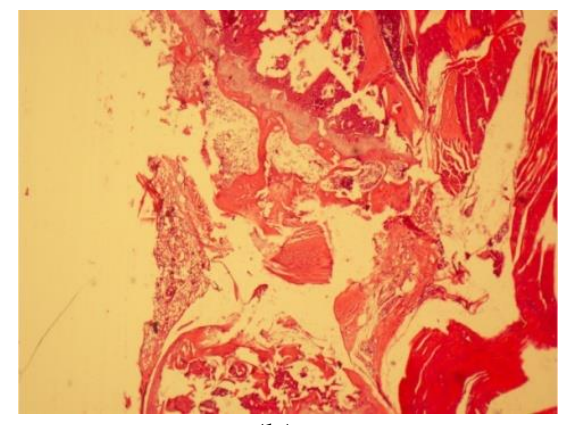

(b)

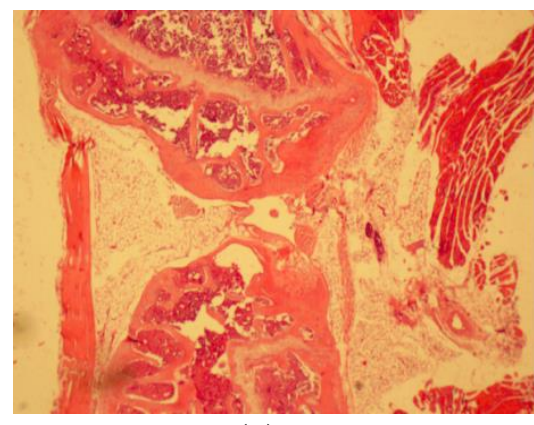

(c)

Figure 6 The kidney histology observation of FE group (a); FB group (b), and naïve group (c) with the magnitude of 40x by utilizing of inverted microscope Olympus CKX410.

The naive and FE groups show the smooth surface of the hyaline layer of cartilage. There is no erosion, but the FE group shows a proliferation of the cells in the compact bones. In contrast, the FB group shows the inflamed joint which is structurally damage. The standard of the assessment is published by Leiss (2013), which states the mild arthritis manifestation occurs in the TMPD-treated lupus mice. This result leads to a prediction that the n-butanol fraction could harm the mice joint.

The activity of both fractions tested results in a suggestion that the ethyl acetate fraction of Kalanchoe pinnata (Lmk)Pers could reduce the manifestation of lupus better than the n-butanol fraction. The parameter of total leukocyte, organ index, and histology observation show that the ethyl acetate fraction is appropriate for the further research.

\section{CONCLUSION}

The ethyl acetate fraction of Kalanchoe pinnata (Lmk)Pers has the higher immunosuppressant activity than the n-butanol fraction in order to repair the disorder occurred in the TMPD-treated lupus mice. However, further research is needed to prove the mechanism.

\section{ACKNOWLEDGEMENTS}

This research was funded by DIPA PNBP 2015 Faculty of Pharmacy Universitas Mulawarman (Grant number 1787/UN17.12/HK/2015) and BPPDN Scholarship for Indonesian doctorate student (Grant number: 906.8/E4.4/2015).

\section{REFERENCES}

1. Abu-Shakra M., Urowitz M.B., Gladman D.D., Gough J. 1995. Mortality studies in systemic lupus erythematosus. Results from a single center. I. Causes of death, The Journal of Rheumatology, 22(7), 1259- 1264

2. Bertoli A.M., Alarcon G.S. 2007. Epidemiology of systemic lupus erythematosus. In: Tsokos GC, Gordon C, Smolen JS. A companion to rheumatology Systemic lupus erythematosus. Philadelphia. Mosby, 1-18

3. Calvani N., Satoh M., Croker B.P., Reeves W.H., And Richards H.B., 
2003. Nephritogenic Autoantibodies But Absence Of Nephritis In Il12p35-Deficient Mice With PristaneInduced Lupus, Kidney International, (64) 897-905

4. Comte D., Karampetsou M.P., Tsokos G.C. 2015.T Cells as a Therapeutic Target in SLE, Lupus,(24), 351-363

5. Cruz E.A., Reutera S., Martina H., Dehzada N., Muzitano M., Costa S.S., Rossi-Bergmann B., Buhla R., Stassend M., Taubea C., 2012. Kalanchoe pinnata inhibits mast cell activation and prevents allergic airway Disease, Phytomedicine, (19), 115121

6. Danchenko N., Satia J.A., Anthony M.S. 2006. Epidemiology of systemic lupus erythematosus: a comparison of worldwide disease burden. Lupus, 15(5), 308-18

7. Ferreira RT., Coutinho MAS, CarmoMalvar D., Costa EA, Florentino IF, Costa SS and Vanderlinde FA. 2014. Mechanisms Underlying the Antinociceptive, Antiedematogenic, and AntiInflammatory Activity of the Main Flavonoid from Kalanchoe pinnata, Evidence-Based Complementary and Alternative Medicine Volume 2014, Article ID 429256, 8 pages

8. Grossman JM, 2009. Lupus arthritis, Best Practice \& Research Clinical Rheumatology, 23; 495-506

9. Jacobsen S., Petersen J., Ullman S., Junker P., Voss A., Rasmussen J.M., et al. 1999. Mortality and causes of death of 513 Danish patients with systemic lupus erythematosus,

\section{ABBREVIATIONS}

ACR: American College of Rheumatology

SLICC: Systemic Lupus Collaborating Clinics

FE: fraction of ethyl acetate

FB: fraction of $n$-butanol

TMPD: $\quad$ 2,6,10,14 tetramethylpentadecane
Scandinavian Journal of

Rheumatology, 28(2),75-80

10. Leiss H, Niederreiter B, Bandur T, Schwarzecker B, Blu S, Steiner G, Ulrich W, Smolen JS, Stumvoll GH.2013. Pristane-induced lupus as a model of human lupus arthritis: evolvement of autoantibodies, internal organ and joint inflammation, Lupus, (22), 778-792

11. Reeves HW, Lee PY, Weinstein JS, Satoh M, and Lu L, 2009. Induction of autoimmunity by pristane and other naturally occurring Hydrocarbons, Trends in Immunology; 30(9): 455464

12. Rifa'i M, 2011. Protective Effect of CD4+CD25+ Regulatory T Cells on Mice Model of Rheumatoid Arthritis, Annales Bogorienses, 15(1), 1-7

13. Salido EO and Manapat HM., 2010. Epidemiology of systemic lupus erythematosus in Asia, Lupus, 19(12), 1365-1373

14. Satoh M, Richards HB, Reeves WH.1999. Pathogenesis of autoantibody production and glomerulonephritis in pristane-treated mice: an inducible model of SLE. In: Tsokos GC, Kammer G, editors. Lupus: Molecular and cellular pathogenesis. Humana Press; p. 399416

15. Tieng AT, Sadow CA, Jay G, Putterman C. 2011. Diffuse Calcification of the Spleen: A Novel Association with Systemic Lupus Erythematosus, Seminar of Artheritis and Rheumatology (41); 187-193 